\title{
Favoritos do público: uma análise das práticas de leitura da comunidade virtual Skoob
}

Rejane Pivetta de Oliveira"

\section{Resumo}

Este artigo analisa práticas de leitura da comunidade de leitores participantes da rede social colaborativa brasileira denominada $S k o o b$, buscando compreender, com base nos comentários manifestados pelos membros dessa comunidade em relação às suas obras "favoritas", quais são os parâmetros que orientam sua leitura. Partimos de uma concepção de literatura como prática cultural que não prescinde da análise dos modos particulares de leitura e significação dos textos, considerando o conceito de "comunidades interpretativas" (FISH, 1980).

Palavras-chave: Leitura. Rede virtual Skoob. Comunidades interpretativas.

\section{Leitura, literatura e comunidade virtual}

As práticas de leitura e os modos de significar essa experiência sofrem mudanças significativas no contexto contemporâneo de oferta massiva e diversificada de bens culturais, em que o livro e a literatura não mais existem autonomamente, mas numa relação estreita e convergente com outros meios, linguagens, produtos, agentes e modos de interação social. Um fenômeno, hoje, bastante comum é a existência de comunidades virtuais de leitores, em que é possível acompanhar lançamentos, participar de promoções, recomendar

Doutora em Letras, área de Teoria da Literatura (PUCRS), professora do Programa de Pós-Graduação em Letras UniRitter.

Data de submissão: mar. 2015 - Data de aceite: maio 2015 http://dx.doi.org/10.5335/rdes.v11i1.4968 
e trocar livros, formar grupos de discussão sobre autores e obras, postar críticas e fazer comentários sobre o que é lido, entre outras inúmeras ações desencadeadas pelas possibilidades de interação oferecidas aos leitores conectados em rede.

A existência dessas comunidades virtuais oferece aos estudiosos da literatura um território aberto à exploração de dados sobre práticas leitoras, usos e concepções sociais da literatura, ainda com pouca atenção por parte da pesquisa acadêmica. Com o propósito de compreender aspectos desse fenômeno, este trabalho apresenta resultados iniciais da análise sobre preferências de leitura da comunidade de leitores participantes da rede social colaborativa brasileira denominada Skoob (http://www.skoob. com.br/), a qual reúne leitores para trocar sugestões e comentários sobre literatura.

Trata-se, assim, de uma análise que procura investigar a literatura inserida no sistema cultural contemporâneo, como manifestação presente e atuante nas práticas de leitura e interpretação cotidianas de leitores que interagem e interferem social e culturalmente por meio dos textos, no espaço virtual. Consideramos, como hipótese de trabalho, que os modos de leitura, manifestados na comunidade virtual, permite-nos compreender o lugar social e cultural da literatura, deslocado de seu caráter de objeto autônomo ${ }^{1}$ e altamente canonizado, segundo parâmetros da comunidade intelectual e acadêmica.
Consideramos que, nas escolhas de leitura e na interpretação das obras, interferem fatores culturais que ultrapassam os limites dos conteúdos e referências textuais. $\mathrm{O}$ fenômeno literário é em si mesmo uma prática cultural, que participa de modo mais amplo da cultura, entendida antropologicamente como um sistema estruturador de significados, de acordo com Clifford Geertz (1989). A própria interação entre texto e leitor é regida por regras culturalmente construídas, que organizam o convívio humano em sociedade. Se considerarmos a cultura como matriz de significações (Geertz, 1989), então, na interpretação do texto, é preciso tomar em conta as "regras do jogo" que orientam as práticas de leitura em comunidades específicas. Nesses termos, o exercício hermenêutico não se refere estritamente aos signos textuais, mas também aos signos sociais e culturais que estruturam a própria percepção dos textos, da qual decorrem formas de interação.

A investigação aqui proposta privilegia o aspecto cultural da leitura literária, organicamente inserida nas práticas de comunidades leitoras, que compartilham regras, estratégias e referências culturais, as quais determinam um certo consenso na atividade interpretativa. Sob esse ponto de vista, podemos entender que a leitura - que já começa pelo tipo de obra lida - realiza-se segundo o que Stanley Fish (1980) denominou de "comunidade interpretativa", que supõe um conjunto de interesses, preocupações, modos de pensar 
e valores, a partir do que os textos são entendidos. Segundo Fish,

[...] a comunicação ocorre somente dentro de um tal sistema (ou contexto, ou situação, ou comunidade interpretativa) e que a compreensão conseguida por duas ou mais pessoas é específica a esse sistema e determinada unicamente dentro dos seus limites (FISH, 1992, p. 192).

Para o autor, os consensos interpretativos devem-se menos à estabilidade de significados inerente ao sistema linguístico do que às estratégias de leitura disponíveis, passíveis de serem compartilhadas dentro de uma comunidade. Comunidade interpretativa é, portanto, aquele ponto de intersecção de indivíduos que se agrupam e compartilham regras que tornam a interpretação aceitável e permitem que os seus membros concordem entre si (FISH, 1980, p. 338). A comunidade interpretativa tem em comum um repertório, que consiste, segundo Itamar Even Zohar, não apenas nas regras de "composição" mas também de interpretação e usos do produto cultural (2007-2011, p. 14).

Tal perspectiva converge com os estudos de antropologia da leitura, tal como o feito por Eric Livingston, segundo o qual as práticas de leitura mantêm a comunidade crítica unida e constituem a "mundaneidade" do seu projeto, ou seja, fazem da leitura uma experiência ligada ao mundo da vida, ao "aqui e agora". Segundo o autor,
Uma antropologia da leitura começa limpando a conversa sobre leitura para examinar as práticas de leitura em si mesmas, ela busca os fenômenos da leitura sob o discurso fundamentado, e procura as origens da argumentação fundamentada nas práticas de leitura. A viabilidade do projeto antropológico está em restituir para a leitura a sua concretude como uma atividade real - as práticas culturais inspecionáveis de uma comunidade (1995, p. 5, tradução nossa).

É importante tomarmos em conta, a partir da afirmação do autor, que uma antropologia da leitura evita trabalhar com concepções prévias sobre a leitura, por isso, deve começar por "limpar o terreno" dos discursos estabelecidos sobre o tema, ocupando-se das práticas de leitura em si mesmas, promovidas pela atuação humana em comunidade. A abordagem antropológica considera que as práticas de leitura correspondem a esquemas culturais. A cultura aqui é entendida numa perspectiva semiótica, conforme formulação de Clifford Geertz, para quem o homem é essencialmente um animal amarrado a "teias de significados que ele mesmo teceu". Para esse autor, a cultura é justamente "essas teias e sua análise", um campo de conhecimento dado à interpretação, à "procura do significado" (1989, p. 4).

Se a cultura é formada por manifestações humanas que comportam significados, então a leitura, em si mesma, enquanto ação, é um significante a ser interpretado, simultaneamente aos significados depreendidos do texto. Portanto, cabe não apenas a leitura do texto, como também a do próprio ato 
de ler e interpretar, como prática que reúne e identifica os membros de uma comunidade.

Considerada na perspectiva antropológica, a leitura, como produção cultural, torna-se um meio de acesso ao conhecimento das características de uma das atividades centrais para a compreensão do homem e da sua situação no mundo, como membro de um grupo social. Se a cultura tem se tornado a categoria privilegiada para o conhecimento do homem, então o trabalho de leitura (ação, prática empreendida pelo homem) assume um papel de destaque, justamente por permitir conhecer as regras sociais envolvidas no processo de construção de sentidos, reveladoras de concepções, valores e comportamentos de diferentes comunidades de leitores face aos textos literários. Tal abordagem exige que abandonemos noções universais sobre o que seja não apenas a leitura, mas também a literatura, válidas para quaisquer que sejam as comunidades interpretativas, permitindo-nos conhecer o que as pessoas fazem efetivamente com os textos, como se comportam diante deles e o que essa leitura revela da posição desses leitores no mundo.

É necessário, pois, num primeiro momento, aproximarmo-nos da comunidade de leitores, cujas práticas desejamos conhecer.

\section{Skoob: território virtual de leitura}

O Skoob é uma comunidade virtual de leitores (http://www.skoob.com.br/), apresentada nos seguintes termos, segundo a Wikipédia:

Skoob é uma rede social colaborativa brasileira para leitores, lançada em janeiro de 2009 pelo desenvolvedor Lindenberg Moreira. O site tornou-se um ponto de encontro para leitores e novos escritores, que trocam sugestões de leitura e organizam reuniões em livrarias. Seu nome deriva da palavra books ("livros", em inglês), ao contrário.

Atualmente permite interatividade com outras redes sociais, como o Twitter e o Facebook, bem como com lojas de comércio eletrônico, por exemplo: Saraiva, Americanas. com e Submarino. Através de cadastro, é possível listar o que você está lendo, o que já leu, o que pretende ler, o que está relendo e quais leituras foram abandonadas, formando assim uma "estante" virtual. O sistema tem um "paginômetro", que soma as páginas dos livros marcados como já lidos, além de uma média de páginas. Títulos ainda ausentes no banco de dados podem ser adicionados pelos próprios usuários, que também podem compartilhar suas opiniões sobre as obras através de avaliações com estrelas, de uma a cinco, e resenhas. Atualmente o Skoob tem mais de 1.200.000 usuários cadastrados.

Possui também a funcionalidade denominada "PLUS", onde os usuários podem disponibilizar seus livros para troca com outros usuários da rede social (Disponível em: > http://pt.wikipedia.org/wiki/Skoob>. Acesso em: 5 abr. 2015).

A literatura conta, hoje, com muitos outros sites e redes sociais especificas, ${ }^{2}$ em que os leitores podem compartilhar informações sobre obras, autores, além da possibilidade de compra e troca de 
livros. O diferencial do Skoob é que se trata de uma comunidade brasileira, que fala a mesma língua, manifestando seus gostos literários, mais ou menos modelados pelo sistema social em que se dão as práticas de produção, circulação e recepção daquilo que todos entendem como literatura. O gosto literário funciona como elemento de agregação e estabelecimento de vínculos entre os usuários da rede, pertencentes a um território comum de trocas e relações sociais. $\mathrm{Na}$ página do Skoob, há uma apresentação que diz que, além de dicas e opiniões de leitura, o site

É também um lugar para fazer novos amigos, tem muita gente que gosta dos mesmos livros que você, nosso papel é ajudá-lo a encontrar essas pessoas e saber quais são suas dicas para a sua próxima leitura. (Disponível em: <http://www.obrigadopelospeixes. com/2010/04/27/skoob-o-que-voce-anda-lendo/>. Acesso em: 5 abr. 2015)

Em matéria publicada no portal do Governo do Estado do Rio de Janeiro, Lindenberg Moreira, idealizador da rede, diz que o Skoob tem como objetivo principal socializar o ato de ler, e ressalta: "A leitura geralmente é algo solitário. Ler um bom livro é maravilhoso e poder compartilhar essa leitura com outras pessoas deixa tudo ainda mais fascinante". Embora não seja um site de relacionamentos, o que acontece efetivamente é o estabelecimento de interações entre os leitores cadastrados no sistema, que descobrem afinidades entre si a partir de suas preferências de leitura. Isso é possível porque os "amigos" podem não apenas indicar seus livros favoritos e manifestar sua opinião a respeito deles, como também podem comentar o que outros disseram sobre os livros lidos.

$\mathrm{Na}$ mesma matéria, Lindenberg Moreira afirma que o site é uma ótima ferramenta para estimular a leitura nas escolas e universidades: "O Skoob pode e deve ser utilizado com esta finalidade. $O$ hábito da leitura, como qualquer outro, precisa ser exercitado e estimulado". Lindenberg aponta ainda uma maneira de os professores utilizarem o Skoob na sala de aula:

O professor pode pedir aos seus alunos que ao terminarem um determinado livro façam uma resenha. Os amigos de turma podem comentar as resenhas dos outros alunos. Durante a leitura, os alunos podem acompanhar os históricos de leitura uns dos outros e trocarem opiniões do que estão achando até o momento. O professor pode levar os questionamentos de cada um para sala de aula e criar um debate ao vivo. Certamente, essa troca entre eles iria estimular e tornar tudo mais prazeroso". (Disponível em: <https://archive.today/ TwnCc\#selection-507.1-559.176>. Acesso em: 5 abr. 2015).

A internet, nesse caso, funciona como uma ferramenta de estímulo à leitura de livros editados em papel, demonstrando claramente que esse ainda é o suporte privilegiado da literatura. Além disso, redes como a Skoob favorecem o debate e a circulação de ideias sobre os modos de leitura do texto, oferecendo-se como material de grande utilidade para a pesquisa sobre a recepção literária. ${ }^{3}$ 


\section{Preferências literárias dos leitores da rede Skoob}

Os dados aqui apresentados são relativos ao item Favoritos, que estabelece uma listagem dos cem livros mais votados pelos leitores do Skoob, segundo consulta realizada no dia 5 de abril de 2015. Os dados apurados, entre os dez títulos favoritos, revelam a seguinte distribuição:

- O livro mais votado é A menina que roubava livros, do escritor australiano Markus Zusak, com 26.855 votos.

- O segundo lugar é ocupado pela obra do norte-americano John Green, $A$ culpa é das estrelas, com 22.617 votos, mesmo autor de Quem é você, Alasca, que aparece na lista na $61^{\mathrm{a}}$ posição, com 6.555 votos.

- Os títulos da série Harry Potter, da escritora inglesa J. K. Rowling, comparecem entre as os dez primeiros classificados, na seguinte ordem:

$\rightarrow 3^{\circ}$ lugar: Harry Potter e as relíquias da morte, v. 7, com 22.907 votos;

$\rightarrow 4^{\circ}$ lugar: Harry Potter e a pedra filosofal, v. 1, com 21.811 votos;

$\rightarrow 5^{\mathrm{o}}$ lugar: Harry Potter e o prisioneiro de Azkaban, v. 3, com 21.017 votos;

$\rightarrow 7^{\circ}$ lugar: Harry Potter e o enigma do príncipe, v. 6, com 18.989 votos;

$\rightarrow$ 8 lugar: Harry Potter e o cálice de fogo, v. 4, com 18.561 votos;

$\rightarrow 10^{\circ}$ lugar: Harry Potter e a Ordem da Fênix, v. 5, com 18.023 votos). ${ }^{4}$
- Na sexta colocação está $O$ Pequeno Príncipe, do francês Antoine de Saint-Exupèry, com 19.493 votos.

- Em 9o lugar está Jogos vorazes, de Suzanne Collins, com 17.561 votos.

São muitas as possibilidades de recolher e interpretar os dados na exploração das preferências de leitura dos leitores da comunidade Skoob. Neste momento, vamos nos ater a considerações gerais sobre a situação dos dez livros preferidos, de modo a construirmos aproximações iniciais sobre comportamentos e padrões de leitura.

- O romance A menina que roubava livros, primeiro da lista, foi publicado originalmente em 2005 , e sua $1^{\mathrm{a}}$ edição no Brasil é de 2007, pela Editora Intrínseca. Em 2013, a obra foi adaptada para o cinema, com direção de Brian Percival.

- A culpa é das estrelas, também da Editora Intrínseca, foi lançado no Brasil em 2012, mesmo ano da edição original em inglês. Em junho de 2014 estreia o filme baseado no livro, com direção de Josh Boone.

- Quanto à série Harry Potter, o primeiro volume (publicado originalmente em 1997) foi lançado no Brasil em 2000, pela Editora Rocco.O último volume da série, o $\mathrm{n}^{-} 7$, foi lançado em 2007, exatamente 10 anos após o primeiro. Todos os volumes da série foram adaptados para o cinema, a partir de 2001. O filme Harry Potter e as relíquias da morte 
( $3^{\circ}$ da lista) foi produzido em duas partes, a primeira com estreia em 2010 e a segunda em 2011.

- Na lista dos dez primeiros colocados, O Pequeno Príncipe, na sexta posição, é o livro mais antigo (a primeira edição é de 1943), e também é o único escrito em língua original que não o inglês, mas o francês. A história de Saint-Exupèry é uma das mais traduzidas no mundo (para cerca de 160 línguas) e já teve entre 400 a 500 edições. Em 1974, a obra transformou-se em um musical para o cinema, dirigido por Stanley Donen. Na década de 1980 foi criada série de desenho animado As aventuras do Pequeno Príncipe, e muitas são as adaptações para o teatro, em diversas montagens no Brasil. A personagem ainda hoje inspira a criação de muitos produtos produzidos em escala industrial.

- Jogos vorazes é o primeiro volume da trilogia ${ }^{5}$, publicado nos Estados Unidos em 2008 e, no Brasil, em 2010, pela editora Rocco. Em 2012, virou filme, dirigido por Gary Ross.

No que se refere a aspectos relacionados ao gênero e ao conteúdo das obras, saltam à vista algumas semelhanças entre elas. Assim, A menina que roubava livros e A culpa é das estrelas são obras que remetem a situações ditas "reais", baseadas em fatos da experiência dos autores $^{6}$. Destaca-se ainda, nesses dois romances, o sofrimento dos seus prota- gonistas, os quais vivem sob condições trágicas impostas pelo destino. Além disso, as obras apelam para personagens jovens, que passam por momentos de grandes dificuldades e desgraça, em que a morte é uma ameaça permanente. No primeiro caso, trata-se de uma menina, Leslie, no contexto da Segunda Guerra Mundial e das atrocidades da Alemanha hitlerista. O segundo livro aborda a situação de jovens diagnosticados com câncer.

Harry Potter, por sua vez, é um enredo que podemos classificar como de aventura e de fantasia, recheado de seres sobrenaturais e poderes mágicos, em que as personagens representam forças do bem e do mal, cabendo ao herói Harry Potter, um garoto que descobre seus poderes mágicos no aniversário de 11 anos, o papel de desvendar segredos e fazer-se mais forte que os poderes da morte que querem liquidá-lo.

O Pequeno Príncipe também apresenta um mundo de fantasia de uma criança, mas, diferente de Harry Potter, baseado na ação, está repleto de passagens líricas, reflexivas e filosóficas, sendo lembrado por sentenças antológicas, como: "Só se vê bem com o coração, o essencial é invisível aos olhos"; ou "Tu te tornas eternamente responsável por aquilo que cativas", entre outras tantas. Comum ainda com Harry Potter é o fato de a obra atingir públicos de todas as faixas etárias: crianças, adolescentes e adultos. 
Jogos vorazes é uma mistura de reality show e video game, envolvendo também personagens jovens de doze a dezoito anos, convocados pelo poder central que governa os doze distritos do país, para participar de competições, transmitidas ao vivo pela televisão, em que sai vencedor aquele que eliminar os demais jogadores. Porém, a regra do jogo é subvertida, pois resta na competição um casal unido por sentimentos de solidariedade e amor.

Uma visão geral dos dez livros favoritos dos leitores do Skoob permite-nos identificar que são histórias com alta carga dramática, seus enredos envolvem personagens jovens que sofrem abandono, rejeição, maus tratos, perdas, perseguição, solidão. A presença da morte em todas as narrativas defronta os personagens com o destino, componente que confere uma nota trágica às histórias. Muito embora a presença implacável da morte (em A menina que roubava livros ela chega a ser uma personagem) assombre a vida das personagens (todas elas experimentam a dor e o sofrimento da perda de alguém a quem amavam muito, seja por laços familiares, amorosos ou de amizade), o sofrimento parece ser recompensado por uma dose de esperança, por um esforço de superação que dá novo sentido à vida e confiança no futuro. $O$ Pequeno Príncipe talvez seja um tanto dissonante em relação às demais obras, uma vez que seu final deixa no ar uma nota de desilusão e desencanto com o mundo. Em todo o caso, o consolo pa- rece não desaparecer, porém ele não se encontra no futuro, mas na nostalgia do passado, em uma infância feliz.

Para uma análise mais conclusiva sobre a identificação de padrões de leitura dos leitores da comunidade Skoob, é necessário atentar para os comentários por eles postados sobre as suas obras favoritas. Neste estudo, vamos focalizar a amostragem dos dois romances colocados no topo da lista: A menina que roubava livros e A culpa é das estrelas.

\section{Indicativos de parâmetros críticos de leitura: A menina que roubava livros e A culpa é das estrelas}

Apresentamos aqui uma análise inicial dos dados coletados nas resenhas publicadas sobre as obras A menina que rouvaba livros e A culpa é das estrelas, considerando como corpus as postagens mais recentes dos leitores, feitas no período de $1^{\circ}$ de janeiro a 4 de abril de 2015 . Em relação à primeira obra, $\mathrm{o}$ Skoob registra um total de 2.308 resenhas; no segundo caso, são contabilizadas 3.106 resenhas. Para efeito deste trabalho, selecionamos as resenhas mais recentes, postadas no período de $1^{\circ}$ de janeiro de 2015 a 5 de abril de 2015, contabilizando, ao todo 149 resenhas (60 sobre A menina que roubava livros e 89 sobre A culpa é das estrelas). Não levaremos em conta a relevância estatística dos dados tomados como base para análise, por isso, as conclusões a 
que chegarmos não serão generalizadas, servindo apenas como indicativas de hipóteses a serem verificadas. Para resultados mais fidedignos e abrangentes, reconhecemos a necessidade de submeter os dados a softwares mais especializados de análise qualitativa de dados.

Neste trabalho, para análise do corpus de resenhas, valemo-nos da fer-

Figura 1 - Nuvem de palavras de a partir das resenhas de A menina que rouvava livros

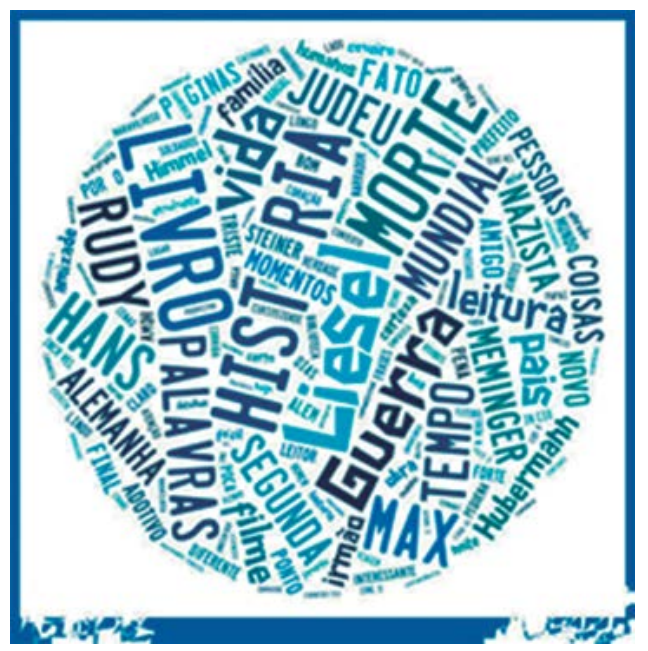

As palavras mais destacadas (em tamanho maior e mais centralizadas) na "nuvem" representativa de cada uma das obras foram agrupadas em seis catego- ramenta tagxedo (http://www.tagxedo. com/app.html), disponível gratuitamente na internet, que permite a criação de "nuvens de palavras", segundo o número de ocorrência dos vocábulos, ao submetermos os textos ao programa ${ }^{7}$. $O$ resultado a que chegamos pode ser conferido a seguir:

Figura 2 - Nuvem de palavras de a partir das resenhas de A culpa é das estrelas

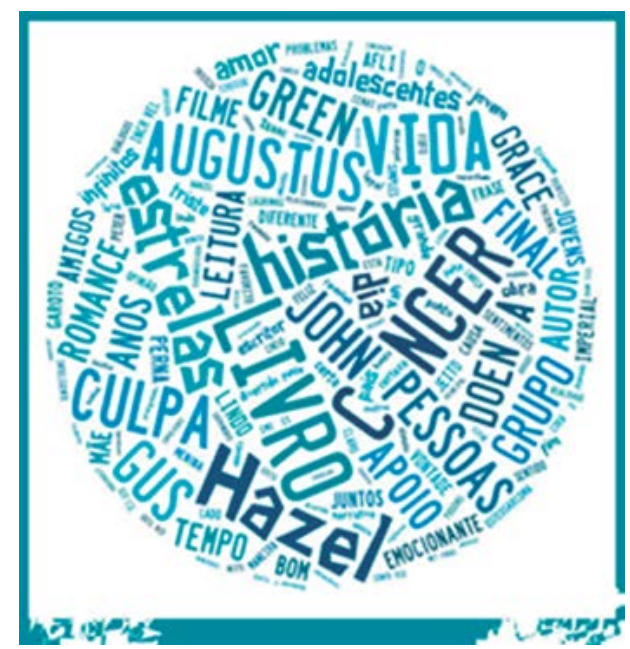

rias, que identificam orientações comuns de leitura, conforme podemos observar na tabela a seguir: 


\begin{tabular}{|c|c|c|c|c|}
\hline \multirow[b]{2}{*}{ Categoria } & \multicolumn{2}{|c|}{ A menina que roubava livros } & \multicolumn{2}{|c|}{ A culpa é das estrelas } \\
\hline & Palavras & $\begin{array}{l}\text { Número de } \\
\text { ocorrências }\end{array}$ & Palavras & $\begin{array}{l}\text { Número de } \\
\text { ocorrências }\end{array}$ \\
\hline Obra de referência & $\begin{array}{l}\text { Livro } \\
\text { Filme }\end{array}$ & $\begin{array}{l}336 \\
114 \\
\end{array}$ & $\begin{array}{l}\text { Livro } \\
\text { Filme }\end{array}$ & $\begin{array}{r}336 \\
94 \\
\end{array}$ \\
\hline Personagens & $\begin{array}{l}\text { Liesel (Meminger) } \\
\text { Morte } \\
\text { Max } \\
\text { Rudy } \\
\text { Hans (Hubermann) } \\
\text { Pais } \\
\text { Rosa }\end{array}$ & $\begin{array}{l}318 \\
277 \\
226 \\
212 \\
199 \\
150 \\
101\end{array}$ & $\begin{array}{l}\text { Grace Hazel } \\
\text { Augustus Waters } \\
\text { Mãe } \\
\text { Pais } \\
\text { Houten } \\
\text { Peter }\end{array}$ & $\begin{array}{r}318 \\
213 \\
67 \\
47 \\
34 \\
29\end{array}$ \\
\hline $\begin{array}{l}\text { Aspectos do tema/ } \\
\text { enredo }\end{array}$ & $\begin{array}{l}\text { Morte } \\
\text { S. Guerra Mundial } \\
\text { Vida } \\
\text { Tempo } \\
\text { Judeu } \\
\text { Pais } \\
\text { Mãe } \\
\text { Alemanha } \\
\text { Nazista } \\
\text { Fato } \\
\text { Rua } \\
\text { Família }\end{array}$ & $\begin{array}{r}277 \\
259 \\
241 \\
177 \\
158 \\
150 \\
130 \\
114 \\
109 \\
97 \\
94 \\
82 \\
\end{array}$ & $\begin{array}{l}\text { Câncer } \\
\text { Vida } \\
\text { Doença } \\
\text { Grupo } \\
\text { Pessoas } \\
\text { Apoio } \\
\text { Dia } \\
\text { Anos } \\
\text { Tempo } \\
\text { Amor } \\
\text { Adolescente } \\
\text { Amigos } \\
\end{array}$ & $\begin{array}{r}297 \\
259 \\
177 \\
150 \\
136 \\
130 \\
124 \\
119 \\
94 \\
85 \\
82 \\
75 \\
\end{array}$ \\
\hline $\begin{array}{l}\text { Manifestação de } \\
\text { juízos e avaliações }\end{array}$ & $\begin{array}{l}\text { Novo } \\
\text { Grande } \\
\text { Emocionante } \\
\text { Triste } \\
\text { Bom } \\
\text { Interessante } \\
\text { Forte } \\
\text { Lindo } \\
\text { Fácil } \\
\text { Boa } \\
\text { Envolvente } \\
\text { Cativante } \\
\text { Incrível } \\
\text { Maravilhoso } \\
\text { Diferente }\end{array}$ & $\begin{array}{l}85 \\
60 \\
48 \\
46 \\
37 \\
28 \\
35 \\
29 \\
30 \\
28 \\
24 \\
20 \\
24 \\
21 \\
37 \\
\end{array}$ & $\begin{array}{l}\text { Bom } \\
\text { Emocionante } \\
\text { Lindo } \\
\text { Grande } \\
\text { Triste } \\
\text { Diferente } \\
\text { Divertido } \\
\text { Interessante } \\
\text { Incrível } \\
\text { Leve } \\
\text { Legal }\end{array}$ & $\begin{array}{l}61 \\
53 \\
50 \\
47 \\
43 \\
38 \\
36 \\
29 \\
28 \\
25 \\
24\end{array}$ \\
\hline Semântica literária & $\begin{array}{l}\text { História } \\
\text { Leitura } \\
\text { Palavras } \\
\text { Personagens } \\
\text { Markus Suzak } \\
\text { Páginas } \\
\text { Final } \\
\text { Narrativa } \\
\text { Narradora } \\
\text { Obra } \\
\text { Leitor } \\
\text { Autor } \\
\text { Frases } \\
\text { Biblioteca } \\
\text { Enredo } \\
\text { Literatura }\end{array}$ & $\begin{array}{r}297 \\
143 \\
187 \\
101 \\
75 \\
67 \\
58 \\
39 \\
56 \\
47 \\
35 \\
29 \\
25 \\
23 \\
22 \\
11\end{array}$ & $\begin{array}{l}\text { História } \\
\text { John Green } \\
\text { Final } \\
\text { Romance } \\
\text { Autor } \\
\text { Leitura } \\
\text { Personagens } \\
\text { Leitor } \\
\text { Páginas } \\
\text { Escritor } \\
\text { Frase } \\
\text { Escrita } \\
\text { Narrativa } \\
\text { Diálogos } \\
\text { Romance } \\
\text { Enredo } \\
\text { Literatura }\end{array}$ & \begin{tabular}{r|}
277 \\
187 \\
130 \\
114 \\
105 \\
101 \\
75 \\
63 \\
56 \\
38 \\
35 \\
33 \\
23 \\
22 \\
22 \\
14 \\
13 \\
\end{tabular} \\
\hline
\end{tabular}

Fonte: dos autores. 
Por mais que os dados levantados sejam objetivos e quantificáveis, sua interpretação depende sempre da percepção de quem os examina, na tentativa de captar aspectos e relações que buscam dar coerência a elementos aparentemente dispersos, mas cuja regra de funcionamento é exatamente aquilo que se quer descobrir. Assim, percebemos algumas categorias evocadas no uso recorrente de algumas palavras, que apontam para certas orientações de leitura.

Primeiramente, é digno de nota o fato de as palavras "livro" e "filme" serem referências constantes nos comentários dos leitores, numa via de mão dupla, em que um alimenta o "consumo" do outro. Podemos entender a palavra consumo, aqui, como uma atuação característica da nova condição do leitor no contexto da produção cultural contemporânea. A leitura do livro realiza-se intimamente relacionada às estratégias de marketing do mercado editorial. As obras chegam ao mercado brasileiro como traduções de best sellers de grande sucesso editorial. A menina que roubava livros (The book thief), desde seu lançamento original, em 2005, pela editora australiana Picador e, em seguida, em 2006, pela Knopf, de Nova Iorque, acumula variados prêmios e permaneceu na lista dos mais vendidos do The New York Times por 230 semanas ${ }^{8}$. O lançamento do filme, em outubro de 2013, dirigido pelo britânico Brian Percival $^{9}$, colocou o livro novamente em evidência, motivando uma nova edição da obra, com a mesma capa de divul- gação do filme, acompanhada de uma intensa campanha de marketing, no embalo da publicidade do filme.

Essa trajetória se repete com The fault in our stars, do norte-americano Jonh Green, autor de outros romances voltados ao público jovem ${ }^{10}$. Antes de chegar às livrarias, 150 mil exemplares foram pré-vendidos, com o autógrafo do autor, que usou diferentes cores de caneta, de acordo com uma campanha de votação dos leitores. Logo após o lançamento oficial, o livro já ocupava a primeira posição dos mais vendidos. O filme, de 2014, foi um estrondoso sucesso comercial, precedido de thrailer de divulgação de largo acesso na internet, garantindo que o filme alcançasse milhões de espectadores em todo o mundo, superando em muitos milhões o seu custo de produção. Muitas turnês percorrendo estados norte-americanos foram organizadas pelo estúdio do filme, em que o autor, Jonh Green, e o elenco da produção, apresentavam-se em espetáculos para auditórios lotados, incluindo autógrafos do livro (que a exemplo de A menina que roubava livros, também ganhou uma capa promocional), com fila de mais de cinco horas. 
Capas dos livros: antes e depois do lançamento das adaptações fílmicas
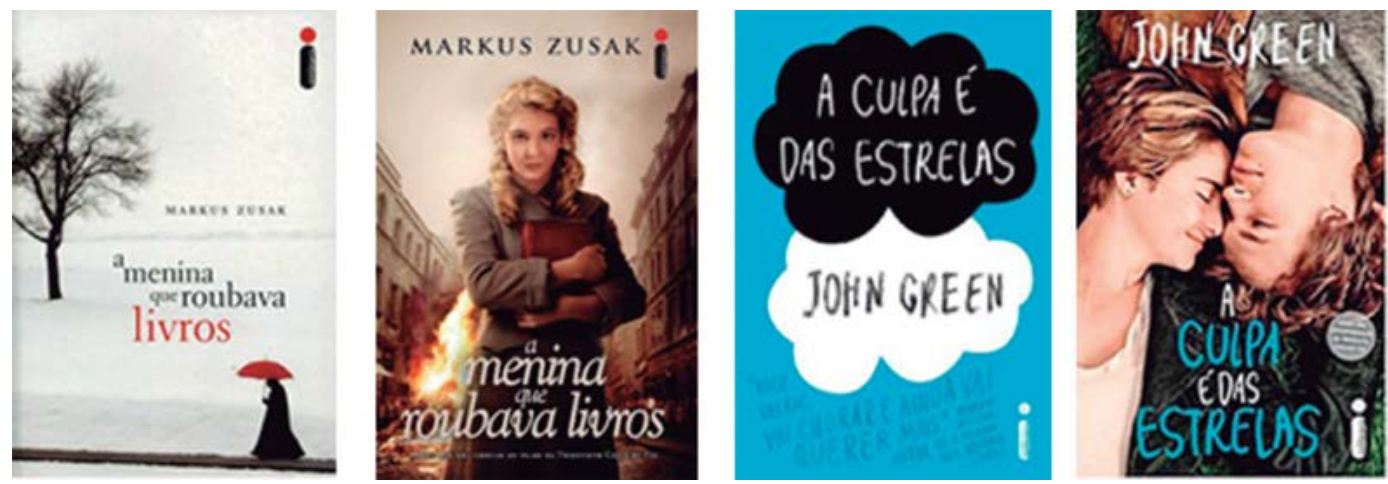

Como vemos, tanto o livro como o filme são produtos que não podem ser vistos fora das negociações com o sistema de produção do mercado cultural. A parceria literatura e cinema mostra-se, nos casos aqui analisados, e em inúmeros outros, mesmo que em graus distintos, muito bem sucedida. As noções de livro como produto e do autor como um produtor ${ }^{11}$ - em nada desprezíveis para o estudo do fenômeno literário na contemporaneidade - levam-nos a indagar sobre suas consequências para $o$ questionamento de valores e concepções sobre a literatura. Devemos lembrar que o fenômeno não se aplica apenas aos best sellers, mas também é evidenciado no caso de clássicos da literatura adaptados para o cinema. ${ }^{12}$ Além disso, não podemos deixar de considerar o caso de escritores que trabalham na produção de roteiros de suas obras, antes mesmo de serem publicadas em livro, e mesmo de escritores que escrevem romances de maneira mais próxima ao roteiro, pensando em uma futura transformação do livro em filme. Hoje também existe um mercado de publicação de roteiros, assim como romance e roteiro dele originado são publicados em um mesmo volume, em edições de luxo, ricamente ilustradas com cenas dos atores e cenários do filme. É todo um contexto de convergência entre as artes, os suportes e as linguagens que coloca aos professores e pesquisadores da literatura novos problemas de investigação ${ }^{13}$.

As situações acima apresentadas não encerram todas as possibilidades de hibridização e interação da literatura com as mídias contemporâneas, operadas desde suas condições de produção, com repercussões na própria forma da escrita. Isso dá mostras de que a instituição literária, embora ainda se revista de certa aura de sacralização derivada do livro como suporte da cultura letrada, na prática já não existe como campo autônomo, pois o produto derivado dessa arte, o livro, ganha força e garante sua sobrevivência justamente por operar na fronteira entre gêneros e mídias. ${ }^{14} \mathrm{~A}$ 
crítica argentina, Josefina Ludmer, no ensaio Literatura pós-autônoma, discute os novos parâmetros de leitura da literatura, a partir de escritas assentadas em dois postulados: a íntima articulação entre o literário, o cultural e o econônico; e a ultrapassam dos limites entre o real e o ficcional. A diversidade de territórios e modos de produção da escrita levam obrigatoriamente à reformulação de categorias que tradicionalmente marcaram a crítica, entre as quais o próprio conceito de literatura, atualmente impensável a partir de critérios abstratos, fora de territórios (ou comunidaes) específicos que determinam relações de produção, circulação e recepção, considerando ainda interações com as instituições e o mercado.

No tocante aos temas abordados na trama ficcional, notamos, pela indicação das palavras mais recorrentes na "nuvem", que as personagens e aspectos relacionados ao conteúdo da ação narrada constituem um eixo predominante seguido pela leitura. A protagonista Liesel Meminger e a personagem narradora, a Morte, são as referências mais citadas nas resenhas de $A$ menina que roubava livros. No caso de A culpa é das estrelas, os comentários recaem sobre o casal de adolescentes Grace Hazel e Augustus Waters.Trata-se de histórias que têm o seu eixo sobre a trajetória dessas personagens, não resultando estranho que os leitores fixem-se sobre elas, tanto quanto em outras que com elas mantêm relações. O comentário de um leitor de A culpa é das estrelas resume bem o papel da personagem na relação de leitura ${ }^{15}$ :Eu gosto de ler tendo como base o ponto de vista de um personagem, porque é assim que a gente vê a vida. E para mim se torna mais fácil entrar na história.
Nas palavras que se referem aos acontecimentos narrados, ressaem aquelas que remetem a fatos da realidade, sejam históricos, tal como "Segunda Guerra Mundial", "Alemanha", "judeu" e "nazista", no caso de A menina que roubava livros; sejam aqueles "inspirados em fatos reais", como "câncer", "doença", "grupo de apoio", no caso de A culpa é das estrelas. Os leitores relacionam de maneira imediata o sofrimento das personagens com aquilo que se passou na experiência das pessoas reais, conforme podemos ler nos fragmentos abaixo, das resenhas postadas no Skoob consideradas nesta análise. Vejamos, primeiramente, o que é dito sobre $A$ menina que roubava livros:

Mesmo sendo apenas ficção, é inevitável imaginar quantas Liesels, Rudys Steiners, Maxes Vanderburgs ou Hanses Hubbermans não existiram realmente na Alemanha Nazista.

[...] só lendo o livro pra você sentir e entender completamente tudo pelo que os personagens passaram (lembrando sempre que os personagens são fictícios, mas pessoas de verdade realmente passaram por todos os momentos terríveis citados na história).

Podemos notar que, embora haja uma distinção entre a ficção e o fato histórico ("mesmo sendo apenas ficção"), por um lado, persiste uma total correspondência entre a experiência de sofrimento das personagens e a passada pelas vítimas do Holocausto, o que nos leva a considerar que a ficção (incluindo o filme) tem o poder de produzir a realidade com seus próprios meios. Em A culpa é das estrelas, por sua vez, a ficção não estabelece contraponto com um evento histórico 
reconhecido, mas confunde-se com a matéria cotidiana da vida:

Não sei como começar a falar desse livro. É que as emoções contidas dentro dessa história... meio complicado distinguir a realidade da ficção, pois o jeito que é contada e o modo como retrata o câncer (geral) torna a leitura tão intíma, tão real.

A obra é um sick-lit, ou seja, os protagonistas tem alguma doença, no caso de ACEDE [sigla de A culpa é das estrelas], trata-se do câncer; e não fantasiam a sua dura realidade, enchendo o livro de reflexões e metáforas sobre vida e morte de forma nua e crua. Ao contrário da fantasia, livros do gênero sick-lit costumam me fazer refletir intensamente, afinal tudo ali poderia e parece ser real.

A própria dimensão da ficção é posta em suspenso, na medida em que ela se identifica a um gênero (a sick-lit), que supostamente não "fantasia" a realidade, mas gera adesão emocional imediata, ao lado de uma saturação de matérias publicitárias, comentários em redes sociais e discussões cotidianas, de tal modo que o realismo deixa de ter um referente verossímil, tornando-se inteiramente uma construção ficcional, assimilada como uma espécie de biografia, ao mesmo tempo dentro e fora das fronteiras da literatura e da realidade. Nos casos aqui analisados, é de se notar que as obras tratam de temas que resultam da experiência pessoal dos escritores, o que não é novidade na literatura - apenas agora assume um novo significado, no contexto da "pós-autonomia" de que fala Josefina Ludmer, em que real, virtual e ficcional têm seus limites cada vez mais atenuados. Assim, podemos afirmar que essas experiências literárias contempo- râneas alteram a noção de ficção, visto que essa não mais se define como uma esfera separada da história passada e da realidade cotidiana.

Em geral, o fato de as obras tomarem a dimensão da realidade é um fator de grande interesse para os leitores, o que se expressa, nos casos aqui estudados, no alto apelo emocional das obras, as quais se assemelham por apresentarem protagonistas jovens, em fase de formação, que vivem experiências de sofrimento, relacionadas à expectativa da morte, seja a própria ou a de membros da família e amigos próximos. Assim, adjetivos como "emocionante" e "triste" aparecem de forma destacada, muitas vezes relacionados entre si, como lemos, por exemplo, sobre A menina que roubava livros:

E mesmo sendo uma história triste em meio à guerra, ela é maravilhosa, envolvente e emocionante.

Forte, emocionante e triste, como qualquer outra história retratada a segunda guerra. No entanto, esta se trata de uma menina que aprendeu amar e odiar as palavras.

O mesmo tipo de apreciação, que reúne de forma positiva tristeza e emoção, é verificada em relação ao romance $A$ culpa é das estrelas:

A Culpa é das Estrelas é um young-adult emocionante que me fez rir e chorar da primeira à última página.

Esse é um dos livros mais tristes, mas ao mesmo tempos, mais emocionantes que já tive o prazer de ler, e nós podemos tirar grandes lições dele.

Mas, nos demais aspectos, a história realmente é bonita e divertida, apesar de ser triste e emocionante. 
A capacidade de a história emocionar, fazer rir e chorar, além de dar lições de vida é a tônica das resenhas. Uma vez que os leitores do Skoob pertencem uma comunidade de fãs (posto que se identificam por elegeram essas obras como suas favoritas), os adjetivos, além dos já referidos, são bastante elogiosos, mostrando ocorrências coincidentes em ambas as obras ("grande", "interessante", "lindo", "incrível", "diferente"). Em sua larga maioria, os leitores recomendam de maneira entusiasmada a leitura das obras, mas isso não significa que não haja avaliações negativas sobre o trabalho dos autores; mesmo que em menor número, elas revelam contrapontos interessantes para pensarmos nos parâmetros de leitura, como notamos, por exemplo, nos comentários dos leitores de A culpa é das estrelas:

Para ser sincero o autor apenas fez o "arroz com feijão" e conquistou o publico [sic] teen com um clichê adolescente.

Talvez eu só não tenha me identificado com o modo que John Green escreva, achei sua linguagem muito voltada à públicos joviais, o que as vezes me irrita um pouco nos livros.

Outro dado interessante é observar, na crítica dos leitores, a recorrência de palavras que remetem à categoria que denominamos de "Semântica literária", por se tratar de termos próprios (mas não exclusivamente) ao universo da literatura, por meio dos quais, de alguma forma, podemos presumir a familiaridade dos leitores do Skoob com a ficção, à medida que partilham de uma mesma metalinguagem, identificando-se, assim, com uma mesma "comunidade interpretativa" (Fish,1980). Trata-se de palavras que, por um lado, designam conceitos abarcados pela teoria literária e, por outro, fazem parte do senso comum, sendo empregados de forma livre, como acontece, por exemplo, com a palavra "romance", referida tanto como forma ficcional, quanto como "relação amorosa". Muitas outras palavras incorporadas ao vocabulário dos leitores - tais como história, narrativa, narrador(a), personagens, diálogos e enredo - indicam que a leitura leva em conta a apropriação de convenções de gênero. Esse dado importa à medida que nos leva à hipótese de que se trata de leitores instruídos por uma educação formal, com hábitos de consumo cultural.

No que respeita ainda à semântica literária, verificamos um conjunto de palavras contempladas na nuvem que claramente apontam para a tríade estabelecida por Antônio Candido, referente aos elementos fundamentais do sistema literáio: autor, obra e leitor.

$\mathrm{O}$ autor (na maior parte das vezes referido com seu nome próprio, e em menor número de casos, como escritor) é uma figura notável no discurso dos leitores. $\mathrm{O}$ autor está diretamente relacionado ao ato de escrever, seu prestígio vem justamente de dominar a arte da escrita. É o que dizem os leitores de $A$ menina que roubava livros:

A escrita do autor é bem enxuta, usando frases curtas e pequenos parágrafos, causando algumas quebras de ritmo em diversos momentos. 
Enfim, o enredo é ótimo, a escrita do autor não é cansativa, na verdade é tão boa que, às vezes, nos esquecemos que é morte narrando aquilo.

$\mathrm{O}$ autor escreve de uma forma diferente. Muitas vezes nos dá a "manchete" ou algumas pistas de fatos que vão ocorrer e depois narra os acontecimentos que culminam no fato anunciado anteriormente.

De igual maneira se manifestam os leitores de A culpa é das estrelas:

A escrita de John Green é perfeita e envolvente. Enquanto se lê, tem-se a impressão de estar assistindo às cenas, descritas em primeira pessoa, por Hazel, apenas o necessário para ambientar o enredo.

Gosto de como John Green escreve, é bem diferente de todas as outras estórias que usam doenças apenas para tentar fixar uma ideia superficial e melodramática.

O John Green escreve com tanto sentimento, tanta emoção... A escrita é completamente envolvente. É um livro rápido de ser lido por conta disso. Ele é incrível, me conquistou.

O escritor é tido em alta consideração, apreciado por suas qualidades excepcionais de criação, merecendo os aplausos e a gratidão dos leitores. A centralidade do escritor sinaliza a permanência da imagem romântica do gênio, como explicitamente manifestam os leitores de A menina que roubava livros:

Um livro que superou todas as minhas expectativas. Incrível, surpreendente, e cruelmente lindo. Markus Zusak é um gênio.

Eu amo esse livro, Markus Zusak foi genial ao criar uma trama que se passa em plena segunda Guerra Mundial, onde a morte narra a estória. Continuei, e em menos de três dias já estava folheando as últimas páginas. O que eu senti? Gratidão. Markus Zusak além de ser um escritor incrível, nos faz "pôr a mão na consciência" sobre o modo com que nos relacionamos com o próximo, sob a perspectiva do "amanhã poderá ser tarde demais".
Os fãs de A culpa é das estrelas também reconhecem no autor qualidades criativas superiores, que o distinguem em sua atividade:

John Green é o autor perfeito que não comete nenhum erro, nenhuma gafe, nada de errado em sua narração cuidadosa, engraçada, de humor negro e ao mesmo tempo com um romance que não é apenas apaixonante para os personagens e sim para os leitores

John Green é um ótimo escritor ele pensou em tudo para criar o livro, pensou em um remédio, pensou em um livro dentro do livro... Toda a história se encaixa perfeitamente, e não é um livro difícil, você só para quando termina... Ele te envolve de uma forma incrível.

Os leitores mantêm com o escritor uma relação de admiração pessoal, estendendo o envolvimento emocional com a obra ao próprio autor ("Após ler esse livro me apaixonei por John Green - nesses nove meses já li quase todos os livros dele"). Talvez esse comportamneto de "fã" esteja relacionado à exposição da imagem do autor na mídia, à facilidade de acesso às suas ideias, por meio de entrevistas, vídeos promocionais, blogs, etc. Tanto Markus Zusak como John Green são autores que se empenham diretamente na divulgação de suas obras, seja envolvendo-se nas campanhas de marketing das editoras e estúdios de cinema, seja realizando turnês para palestras e sessões de autógrafos, seja fomentando debates e disponibilizando materiais em suas páginas na internet e nas redes sociais. Assim, ao mesmo tempo que o escritor perde a aura sagrada de figura inacessível e alheia à realidade, sua celebridade é garantida pela exposição 
pública de sua imagem, pelo sucesso de vendas e pelas críticas positivas espalhadas em jornais e sites, que instituem e dão crédito às qualidades de "gênio" da escrita percebidas pelos leitores.

Ao se referirem às obras, notamos que também prevalece no discurso dos leitores manifestações de valor, tanto quanto em relação ao autor, responsável pela criação. Vejamos os termos em que isso aparece nas resenhas de ambas as obras, atentando para os grifos por nós assinalados:

Uma verdadeira obra de arte literária do escritor Mark Zusak.

Grande obra de John Green, revelando as grandes trapaças de uma vida daqueles que contem os sintomas de estar morrendo.

Mas a agilidade de todas as ações não tiraram o brilho da história, continuaram tornando-a uma obra de arte (sobre $A$ culpa é das estrelas).

Autor e obra são termos cercados de apreciações exaltadas - positivas ou negativas - que aqui podemos equiparar ao uso da palavra "literatura", que aparece em diferentes contextos discursivos no discurso dos leitores ${ }^{16}$ :

Simplesmente uma obra prima da literatura atual e que com certeza vivera por séculos e séculos. (sobre A menina que roubava livros)

Devo dizer que sempre tive um certo receio em ler livros "modinhas" pois todo mundo fica lendo e então se acham os maiores fãs de literatura do mundo. (sobre A menina que roubava livros)

Mas livro muito inferior a grandes da Literatura, que merecem muito mais apreço. (sobre A culpa é das estrelas)
Para mim, "A CULPA É DAS ESTRELAS" do escritor norte-americano JOHN GREEN é uma das coisas mais bonitas e singelas de eu já tive a felicidade de ler, uma verdadeira Ode ao amor e a boa literatura.

O conceito de literatura, nesss citações, tanto referenda quanto desqualifica as obras em questão. A "boa literatura" parece seguir tanto critérios de gosto pessoal (“... das coisas mais bonitas e singelas que eu já tive a oportunidade de ler"), como obedecer ao cânone instituído dos "grandes" (embora não sejam aqui citados, podemos deduzir que pertençam à linhagem dos clássicos), em relação aos quais outras obras são julgadas como "livro muito inferior". A verdadeira literatura também é grafada com inicial maiúscula, e parece perdurar no tempo (não se trata de "livros modinhas"). A despeito da produção massiva de livros, tomados de maneira geral pelo mesmo conceito de obra, nos comentários dos leitores é possível perceber a marca de prestígio que impregna a escrita literária, independentemente da atribuição que cada leitor a ela confere.

Por fim, resta-nos agora compreender o papel do leitor, configurado nas interações da Skoob. Antes de mais nada, os leitores são "pares", as resenhas são feitas de leitores para leitores, o que se observa nas formas evocativas muitas vezes presentes nos comentários de A menina que roubava livros, por exemplo: 
Pois bem meus queridos e queridas, acabei por findar mais um livro. E sempre que termino uma boa leitura fico com os dedos coçando para escrever sobre ela. Então, sem mais delongas, vamos roubar algumas palavras e colocá-las logo abaixo. Que me diz, leitor?

Sim, leitor, este livro é sobre palavras.

Contra as estatísticas ou anúncios catastróficos sobre o fim dos leitores, a Comunidade Skoob constitui uma demonstração de que eles não só existem, como são aficionados por livros. São leitores que revelam seu grande interesse pela leitura, entendida como uma experiência mobilizadora da imaginação, de sentimentos e emoções, reflexões e aprendizagens:

Alguns acontecimentos não são descritos de forma explícita, nestes casos, cabe o leitor imaginar e deduzir o que aconteceu. (sobre A Menina que Roubava Livros)

Essa obra do Markus Zusak é o tipo de livro que a maioria dos leitores procura, um livro que te prende já nas primeiras páginas e te faz abrir a mente e imaginar cada cena, e no fim te faz querer mais.

Essa construção faz da escrita mais inteligente e divertida, principalmente porque está subentendida e não subestima o leitor por não explicar o que se quis dizer, apenas diz.

Uma lição de vida e de amor para o leitor levar para sempre. (sobre A culpa é das estrelas)

"A culpa é das estrelas" é cheio de detalhes, apesar da leitura rápida (o que me agrada muito), e extremamente reflexivo. Não reflexivo como um livro tedioso de auto-ajuda [sic]. Reflexivo de acordo com a interpretação de cada leitor.

Devemos lembrar que ambos os romances apresentam personagens leito- ras, tematizam o universo dos livros e a experiência de leitura. Liesel apega-se aos livros como forma de sobrevivência, num tempo em que eles são proibidos e raros de se conseguir - tornando-se, por isso, objetos de desejo da menina, que passa a roubá-los. Os protagonistas de $A$ culpa é das estrelas são admiradores do romance Uma flição imperial, que acaba no meio de uma frase, motivando sua viagem para a Holanda, onde pretendem encontrar com o autor. Desse modo, os romances prefiguram leitores capazes de se deixar "arrastar" pelos livros, em perfeita sintonia com o perfil dos leitores reunidos na comunidade Skoob. Em alguns caos, temos relatos que exemplificam experiências gratificantes de iniciação à leitura, como revelam leitores de A culpa é das estrelas:

Não tenho hábito por leitura, mas uma certa manhã, de um dia que não me lembro, vi o livro na estanque do quarto de minha prima, ele estava lá quietinho. Então me veio aquela vontade de abrir o livro, de conhecer o mundo da leitura, de poder folhear cada página e cada palavra. Com isso peguei o livro emprestado e logo comecei a ler.

A leitura é algo que precisamos resgatar para o nosso dia a dia. Não sou muito fã de livros, mas procure achar aquilo que te interessa, e a Culpa é das estrelas foi o livro que mais gostei, não só pelo romance mas pelo jeito como John Green o escreveu.

Para mim foi uma leitura difícil, pois eu não tenho o hábito de ler, e achei o livro um pouco chato em algumas partes. Mas no final de tudo eu gostei e me surpreendi com o final, porque eu nunca imaginei que seria um Gus que morreria no final. E a lição que eu tiro é que nem todas as histórias de amor tem uma final feliz. 
Enfim, a literatura de John Green é realmente legal e interessante. Você se prende ao livro e querendo ou não, não consegue parar de ler! Recomendo a leitura mais para quem está iniciando no mundo dos livros. Abraços.

A leitura é motivada por um processo de sedução, de conquista do leitor, o que acontece, via de regra, quando esse se sente preso à história, motivado a saber o que vai acontecer "no final". A leitura não se mostra uma atividade inócua, mas tem o poder de provocar mudanças no comportamento do leitor, do que é ilustrativo o comentário de um leitor de A culpa é das estrelas: "John Green transformou uma vítima em uma heroína que inegavelmente transformou muito dos seus leitores".

\section{Reflexões sobre literatura e leitura na rede virtual Skoob}

Embora tenhamos apresentado aqui uma análise de um corpus inicial, os dados levantados fornecem alguns indicativos sobre comportamentos de leitura da comunidade de leitores da rede Skoob, em relação a seus livros eleitos como favoritos.

Primeiramente, precisamos considerar o fato de a comunidade Skoob reunir membros identificados como leitores, o que constitui uma espécie de identidade do grupo. Embora não tenhamos feito estudos sobre o perfil desses leitores dados como formação, classe social, faixa etária, profissão, etc. - podemos inferir que se trata de um público escolarizado, apreciador de livros e cinema, dotado de referências culturais que vão de best sellers a clássicos. Trata-se de leitores que se apresentam como fãs e admiradores, tanto dos livros como dos seus autores, que passam a recomendar para outros leitores.

A menina que roubava livros e A culpa é das estrelas são obras apreciadas por sua capacidade de mexer com os sentimentos do leitor, pelo quanto conseguem prendê-lo às páginas, provocando o desejo de continuidade da leitura. Não é de se estranhar, pois, que dez entre os dez primeiros colocados da lista dos favoritos pertençam ao gênero narrativo, mais especificamente ao romance de aventura. A construção das personagens, ao lado de uma linguagem fácil, associada à leitura e um final surpreendente são elementos agregados à qualidade da história e ao talento do escritor em criar o envolvimento do leitor. $\mathrm{O}$ fato de os leitores fixarem-se na trajetória das personagens e perceberem nelas, na maciça maioria dos casos, exemplos de vida capazes de inspirar e mesmo transformar a vida dos leitores demonstra que elas são modeladas segundo códigos culturais compartilhados por seus intérpretes. Assim, o Holocausto e o câncer terminal de adolescentes, antes de temas estritamente históricos ou científicos, com uma significação precisa, são processados psíquica e culturalmente pelos leitores. Mesmo quando o leitor manifesta contrariedade aos modos de representação da história, eles ainda estão agindo segundo 
convenções absolutamente familiares entre os membros da comunidade. Além disso, como se trata de textos que pertencem ao mesmo gênero, com personagens envolvidas em circunstâncias trágicas e ameaçadas pela morte, confirma-se a tese de Fish de que diversos leitores produzem leituras similares de certos tipos de textos.

A comunidade de leitores do Skoob orienta sua leitura por códigos e convenções culturalmente reconhecidas, as quais articulam os significados das obras lidas, determinando o que Fish denomina de consenso interpretativo. Inclusive a noção de literatura e a metalinguagem a ela associada, demonstra que os leitores do Skoob de fato constituem uma comunidade afinada com o repertório literário.

Outras comunidades de leitores, assim como outros tipos de obras, merecem ser estudadas, a fim de confirmarmos a hipótese de que diferenças culturais e de formas de interação determinam parâmetros de interpretação, formas de significação da literatura e da leitura que extrapolam os limites estritamente textuais. Estudos mais aprofundados são necessários para a análise da presença da literatura no sistema cultural, a partir das interações que estabelece com repertórios provenientes de diversos meios e formas de mediação. A literatura, a despeito de um campo que preserva muito da sua autonomia conquistada no século XIX, parece que retira sua sobrevivência (ao mesmo tempo em que se refuncionaliza) no jogo de autonomia e dependência em relação aos mecanismos de produção, circulação e recepção de produtos e consumos culturais, distintos do campo da cultura erudita em que, confortavelmente, a literatura situava-se no passado, tendo agora que se afirmar em novos termos.

Seja como for, o certo é que tal avaliação não poderá ser feita sem o conhecimento das práticas de leitura de diferentes comunidades, como possibilidade de compreendermos a constituição intrinsecamente social e cultural da literatura, entendida como produção simbólica inseparável das dinâmicas do sistema cultural e das formas de interações humanas concretas no cotidiano contemporâneo.

The favorite of the public: a analysis of reading practices of the virtual community Skoob

\begin{abstract}
This article examines reading practices of the reader's community participants of Brazilian collaborative social network called Skoob, trying to understand, from the comments expressed by members of the community in relation to their "favorite" works, the parameters that guide their reading. We take a conception of literature as a cultural practice that requires analysis of particular modes of reading and meaning the texts, considering the concept of "interpretive communities” (Fish, 1980).
\end{abstract}

Keywords: Reading. Skoob virtual network. Interpretive communities. 


\section{Notas}

1 Segundo Pierre Bourdieu, em As regras da arte (1996), o campo literário alcança sua autonomia no século XIX, para o que concorre a ação de autores como Flaubert e Baudelaire, que transformam em representação os processos envolvidos na criação literária. A autonomia do campo artístico implica a existência de um conjunto de regras e disputas entre agentes, que garantem o seu reconhecimento e a sua legitimação.

2 Exemplos de redes sociais literárias são a Shelfari, a LibraryThing e a Goodreads. Em português, o principal concorrente do Skoob no gênero é $O$ livreiro, que, além da rede social, conta com uma seção de conteúdo, com resenhas e notícias sobre o mercado editorial. $\mathrm{O}$ projeto conta com o apoio do premiado escritor Milton Hatoum, que media debates literários entre internautas num fórum. (Revista Época, acessível em http://revistaepoca.globo.com/ Revista/Epoca/0,,EMI96567-15220,00-REDE S+SOCIAIS+TRAZEM+A+LITERATURA+PA RA+A+INTERNET.html).

3 No âmbito literário, os estudos voltados para a recepção são conhecidos a partir dos trabalhos produzidos pela Estética da Recepção, nos anos de 1960, na Alemanha, cujos principais representantes são Wolfgang Iser e Hans-Robert Jauss. Logo em seguida, nos Estados Unidos, tal perspectiva desenvolve-se com o Reader Response Critcism, a partir de Norman Holland e Stanley Fish.

4 Cabe o registro de que o v. 2 da série, Harry Potter e a câmara secreta, aparece na $11^{\circ}$ posição, com 17.920 votos.

5 Os outros volumes são Em chamas, de 2009 e A esperança, de 2010. Ambos ocupam, respectivamente, a $12^{\mathrm{a}}$ e a $13^{\mathrm{a}}$ posições na preferência dos leitores da comunidade Skoob.

6 Markus Zusak, autor de A menina que roubava livros, revela em vídeos disponíveis na internet, que a história desse livro é inspirada em acontecimentos vividos por membros de sua família. Entre os muito vídeos encontrados, citamos um deles, dividido em três partes: The Book Thief by Markus Zusak - Part 1: the Writing Process (https://www.youtube. com/watch?v=P_lIpugbLB); Part 2: Questions from the Audience (https://www.youtube.com/ watch?v=5sWDy6X8p_o) ; Part 3: a Reading by the Author (https://www.youtube.com/ watch?v=xHawgX9e99E). Já o autor de A cul- pa é das estrelas, John Green, conta episódios inspirado na sua experiência de trabalhar em um hospital para crianças com câncer terminal. Conferir em: John Green fala sobre "A culpa é das estrelas".avi (https://www.youtube.com/ watch?v=ByfSr8N_b1Y).

7 As resenhas foram submetidas à ferramenta, a partir de uma filtragem que considerou apenas substantivos e adjetivos, por considerarmos que tais classes de palavras são indicativas de elementos analíticos de maior interesse para a pesquisa neste momento. Além da organização gráfica das palavras em forma de nuvem, o software permite a identificação do número de ocorrências de todas as palavras, mesmo as que não são imediatamente visíveis na imagem.

8 Disponível em http://en.wikipedia.org/wiki/ The_Book_Thief, acesso em 19/04/2015.

9 Mais conhecido pelas séries da televisão britânica Downton Abbey e North \& South. Disponível em http://en.wikipedia.org/wiki/ Brian_Percival, acesso em 19/04/2015.

10 Títulos lançados pela Editora Intrínseca, na esteira do sucesso de A culpa é das estrelas: Cidade de papel (2013); O teorema Katherine (2013); Quem é você, Alasca (2014)

11 Tal nomenclatura deriva da abordagem que Itamar Even-Zohar faz da literatura, a partir de sua teoria dos polissistemas, ampliando os papéis dos agentes envolvidos no processo de comunicação literária (adaptado do sistema de comunicação de Jákobson). Ao preferir o termo produtor a autor, Itamar atribui outras funções ao "emissor" da mensagem literária (o livro), pois como afirma, a noção de escritor suscita imagens muito específicas, que podem ser inapropriadas (2007-2011, p. 32). Assim, o produtor literário tem a vantagem de considerar que as condições de produção não são externas ao produto (obra), ou seja, não são independentes das normas de repertório (20007-2011, p. 34).

12 Como exemplo, podemos citar filmes baseados em Hamlet e Romeu e Julieta, de Shakespeare; Orgulho e preconceito, de Jane Austin; Madame Bovary, de Flaubert; Alice no País das Maravilhas, de Lewis Caroll, e inúmeros outros.

13 Vera Lúcia Follain de Figueiredo, no artigo "Roteiro, literatura e mercado editorial: o escritor multimídia", chama atenção para o fato de que alguns romances, depois de roteirizados para o cinema, sofrerem alterações em suas edições posteriores (a exemplo de Cidade de Deus, de Paulo Lins), o que faz com que a literatura tenha questionado o seu caráter de obra acabada 
(Disponível em http://www.uff.br/ciberlegenda/ verafollain.pdf. Acesso em 10 abr. 2015).

14 Os tênues limites entre a literatura e os demais produtos culturais também são abordados no artigo de Vera Lúcia Follain de Figueiredo, anteriormente referido.

15 Todos os trechos das resenhas aqui citadas de A menina que roubava livros e A culpa é das estrelas encontram-se na página da Skoob, respectivamente, nos seguintes links: https://www.skoob.com.br/livro/resenhas/7/ edicao:268782 e https://www.skoob.com.br/ livro/resenhas/247555/edicao:277187.

16 A palavra literatura, embora invisível na nuvem, é referida 13 vezes a respeito de A culpa é das estrelas e 11 vezes em relação ao livro $A$ menina que roubava livros.

\section{Referências}

BOURDIEU, Pierre. As regras da arte. Tradução de Maria Lucia Machado. São Paulo: Companhia das Letras, 1996.

BRIAN PERCIVAL. In: WIKIPEDIA, the Free Encyclopedia. Disponível em: <http:// en.wikipedia.org/w/index.php?title=Brian Percival\&oldid=654068063 $>$. Acesso em: 20 abr. 2015.

EVEN-ZOHAR, Itamar. Teoria dos polissistemas. Tradução de Luis Fernando Marozo, Carlos Rizzon e Yanna Karlla Cunha. Revista Translatio, Porto Alegre, v. 5, p. 2-21. 2013

EVEN-ZOHAR, Itamar. Polisistemas de Cultura. Tel Aviv: Universidad de Tel Aviv, Laboratorio de investigación de la cultura, 2007-2011. Disponível em: <http://www. tau.ac.il/ itamarez/works/papers/trabajos/ polisistemas_de_cultura2007.pdf $>$. Acesso em: 20 abr. 2015.

FISH, Stanley. Is there a text in this class? The authority of Interpretative Communities. Harvard University Press, 1980.

FISH, Stanley. Is there a text in this class? Tradução de Rafael Eugenio Hoyos-Andrade. Revista Alfa, São Paulo, 36: 189-206, 1992.
GEERTZ, Clifford. A interpretação das culturas. Rio de Janeiro: LTC, 1989.

JOHN GREEN FALA SOBRE A CULPA É DAS ESTRELAS.avi. Disponível em: <https://www.youtube.com/watch?v=ByfSr8N b1Y>. Acesso em: 20 abr. 2015.

LIVINGSTONE, Eric. An anthropology of reading. Indiana University Press, 1995.

LUDMER, Josefina. Literatura pós- autônoma. Revista de crítica literaria y de cultura, n. 17, jul. 2007. Disponível em: <http:// culturaebarbarie.org/sopro/n20.pdf $>$. Acesso em: 5 abr. 2015.

RESENHAS - A menina que roubava livros. In: SKOOB. Dinponível em: <https:// www.skoob.com.br/livro/resenhas/7/edicao:268782>. Acesso em: 5 abr. 2015.

RESENHAS - A Culpa é das Estrelas. In: SKOOB. Disponível em: <https://www. skoob.com.br/livro/resenhas/247555/edicao:277187>. Acesso em: 5 abr. 2015.

SOCIALIZANDO O ATO DA LEITURA. SKOOB. Disponível em <https://archive. today/TwnCc>. Acesso em: 5 abr. 2014.

SKOOB. In: WIKIPÉDIA, a enciclopédia livre. Flórida: Wikimedia Foundation, 2015. Disponível em: <http://pt.wikipedia.org/w/ index.php?title=Skoob\&oldid=41959138 $>$. Acesso em: 5 abr. 2015.

SKOOB. O que você anda lendo? Disponível em: <http://www.obrigadopelospeixes. com/2010/04/27/skoob-o-que-voce-anda-lendo/>. Acesso em: 5 abr. 2015.

THE BOOK THIEF BY MARKUS ZUSAK Part 1: the Writing Process Disponível em: $<$ https://www.youtube.com/watch?v=P_lIpugbLB>. Acesso em: 20 abr. 2015

'THE BOOK THIEF. In: Wikipedia, The Free Encyclopedia, 20 April 2015, 00:41 UTC, Disponível em: <http://en.wikipedia. org/w/index.php?title=The_Book Thief\&oldid $=657259255>$. Acesso em: $2 \overline{2}$ abr. 2015. 